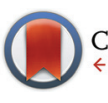

CrossMark \&lick for updates

Cite this: Polym. Chem., 2016, 7, 4833

Received 4th June 2016,

Accepted 23rd June 2016

DOI: $10.1039 / c 6 p y 00965 d$

www.rsc.org/polymers

\section{Sequence-regulated vinyl copolymers with acid and base monomer units via atom transfer radical addition and alternating radical copolymerization $\uparrow$}

\begin{abstract}
Takamasa Soejima, ${ }^{a}$ Kotaro Satoh ${ }^{\star a, b}$ and Masami Kamigaito*a
Main- and side-chain sequence-regulated vinyl copolymers with acid and base monomer units were prepared using atom transfer radical addition (ATRA) and alternating radical copolymerization. A series of maleimide-ended sequence-regulated "oligomonomers" were prepared by ATRA of $t$-butyl acrylate (tBA: $A_{p}$ ) (i.e., a protected acrylic acid (A)) or an amine-functionalized acrylate, (2-(dimethylamino)ethyl acrylate (DMAEA: B)), and styrene (S) followed by an $S_{N} 2$ reaction of furan-protected maleimide (M) anion and its deprotection. The obtained maleimide-ended oligomonomers ( $M-A_{p} S, M-S A_{p}, M-B S, M-S B$ ) were copolymerized with $S$ in alternating reversible addition-fragmentation chain transfer (RAFT) COpolymerizations, resulting in main- and side-chain sequence-regulated copolymers with controlled molecular weights. After deprotection of the $t$-butyl group, the acid and base interactions between the copolymers were evaluated by dynamic light scattering (DLS) of the polymer solutions. All the mixtures resulted in submicron particles, and the size depended on the sequence of acid monomers in the side chains. The effects of the functionalized monomer sequences on the thermal properties were also examined using differential scanning calorimetry (DSC) and thermogravimetric analysis (TGA).
\end{abstract}

\section{Introduction}

Natural functional macromolecules, such as proteins, consist of controlled sequences of "monomers" that possess hydrophobic, hydrophilic, polar, nonpolar, ionic, nonionic, aliphatic, aromatic, acid, base, or other moieties with various properties and functions. The controlled monomer sequences can dictate the shape of macromolecules and the mutual location of each monomer unit in the resulting higher-order structure to endow special properties and functions. However, monomer sequence control in polymer synthesis remains challenging, especially for synthetic vinyl polymers, ${ }^{1-5}$ because chain-growth polymerizations of comonomers typically proceed in a random or statistical fashion.

Many approaches for controlling the monomer sequences in vinyl copolymers have been reported including copolymerization with highly selective propagation, such as alternating

\footnotetext{
${ }^{a}$ Department of Applied Chemistry, Graduate School of Engineering, Nagoya University, Nagoya 464-8603, Japan.E-mail: satoh@apchem.nagoya-u.ac.jp, kamigait@apchem.nagoya-u.ac.jp

${ }^{b}$ Precursory Research for Embryonic Science and Technology, Japan Science and Technology Agency, 4-1-8 Honcho, Kawaguchi, Saitama 332-0012, Japan $\dagger$ Electronic supplementary information (ESI) available. See DOI: 10.1039/c6py00965d
}

copolymerization, ${ }^{6-20}$ template polymerization, ${ }^{21-31}$ sequential multi block copolymerization, ${ }^{32-38}$ iterative single monomer addition reactions, ${ }^{16-18,39-46}$ and other polymerizations of designed monomers. ${ }^{39,41,46-58}$ However, the degree of controllability, number of controllable sequence units, and molecular weights varies. There have been only a few studies on the effects of monomer sequences on the properties and functions of these vinyl copolymers.

Recently, we developed a novel method for controlling the monomer sequences in both the main and side chains of vinyl copolymers using a combination of iterative atom transfer radical additions (ATRAs) and alternating radical copolymerization. ${ }^{16-18}$ In this method, maleimide-ended "oligomonomers" bearing sequence-controlled vinyl monomer units were prepared by iterative ATRAs followed by radical copolymerization with styrene or limonene to afford the 1:1 or $2: 1$ alternating copolymers. The monomer sequence in the short side chains can be perfectly controlled by iterative ATRAs, and the alternating radical copolymerization can result in relatively long main chains with alternating monomer sequences that are statistically governed by the comonomer reactivity ratios. This combined approach generates fairly high molecular weight vinyl copolymers in relatively high yield. In addition, the effects of the monomer sequences on the polymer properties (e.g., solubility and thermal properties) of the sequence-regulated vinyl copolymers were studied. 
In this study, we constructed carboxylic acid- and aminefunctionalized vinyl monomer units as the monomer sequences of the side chains in the vinyl copolymers and investigated the effects of the functionalized monomer sequences on the acid-base interactions between the copolymers. The acid and base monomer units were chosen to be acrylate monomers (i.e., tert-butyl acrylate $\left.\left(t \mathrm{BA}: \mathrm{A}_{\mathrm{p}}\right)\right)$, which is a precursor of acrylic acid (A), and 2-(dimethylamino)ethyl acrylate (DMAEA: B), respectively, and a series of maleimide (M)ended sequence-regulated vinyl dimers with styrene (S) and functionalized acrylates $\left(\mathrm{M}-\mathrm{SA}, \mathrm{M}-\mathrm{A}_{\mathrm{p}} \mathrm{S}, \mathrm{M}-\mathrm{SB}, \mathrm{M}-\mathrm{BS}\right)$ were synthesized using ATRAs (Scheme 1). Then, the sequence-regulated vinyl dimers were radically copolymerized with $\mathrm{S}$ in a $1: 1$ alternating fashion, resulting in main- and side-chain sequence-regulated copolymers with sequenced acid or base units in their side chains. Furthermore, the acid-base interactions of the sequence-regulated copolymers with controlled molecular weights, which were prepared by the RAFT copolymerization, were investigated.

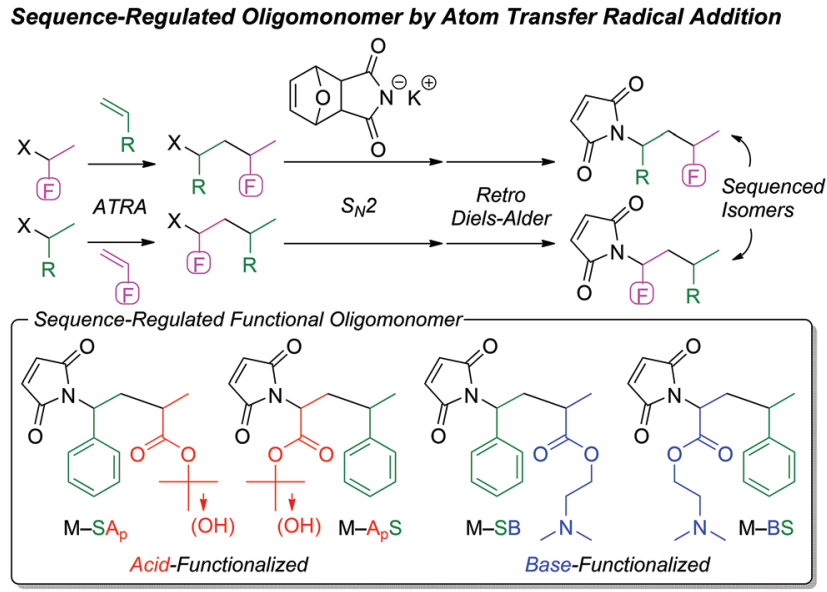

Alternating Radical RAFT Copolymerization of Oligomonomer and Styrene
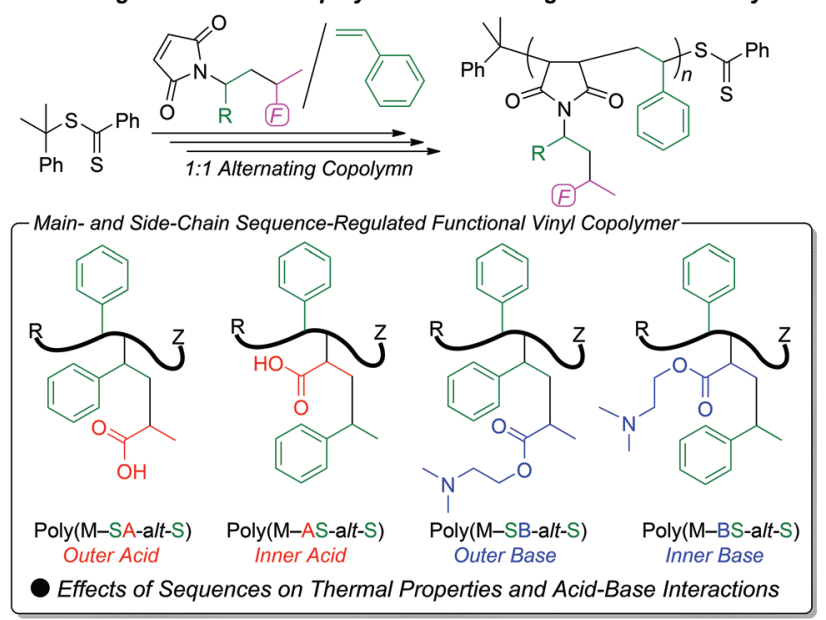

Scheme 1 Sequence-regulated functional oligomonomers via atom transfer radical addition and alternating RAFT copolymerization of oligomonomers and styrene for main- and side-chain sequence-regulated vinyl copolymers with acid and base functions.

\section{Results and discussion}

Synthesis of sequence-regulated oligomonomers with acid and base monomer units by ATRAs

A series of maleimide-ended sequence-regulated acid- or basefunctionalized oligomonomers were prepared by ATRA between $t \mathrm{BA}$, DMAEA, or styrene and their unimer halides followed by $\mathrm{S}_{\mathrm{N}} 2$ reaction between the resulting dimer halides and furan-masked maleimide anion with a retro Diels-Alder reaction to deprotect the furan group.

ATRAs were first conducted between the vinyl monomers $\left(\mathrm{A}_{\mathrm{p}}, \mathrm{B}, \mathrm{S}\right)$ and the excess monomeric halides (1-phenylethyl chloride (Cl-S), 1-phenylethyl bromide (Br-S), $t$-butyl $\alpha$-bromopropionate $\left(\mathrm{Br}-\mathrm{A}_{\mathrm{p}}\right)$, or 2-(dimethylamino)ethyl $\alpha$-chloropropionate (Cl-B)) using $\mathrm{CuBr} / N, N, N^{\prime}, N^{\prime \prime}, N^{\prime \prime}$-pentamethyldiethylenetriamine (PMDETA) or $\mathrm{RuCp}{ }^{*} \mathrm{Cl}\left(\mathrm{PPh}_{3}\right)_{2}$ as the metal catalyst. As previously reported, ${ }^{17,18}$ we selectively employed $\mathrm{RuCp}^{*} \mathrm{Cl}\left(\mathrm{PPh}_{3}\right)_{2}$ for styrene terminal halides $(\mathrm{Cl}-\mathrm{S}$, $\mathrm{Br}-\mathrm{S})$ and acrylate terminal chloride (Cl-B), and CuBr/PMDETA was employed for acrylate terminal bromide $\left(\mathrm{Br}-\mathrm{A}_{\mathrm{p}}\right)$. These ATRAs proceeded as those reported for methyl acrylate (MA) with no functional moieties ${ }^{17,18}$ even though the products gradually decomposed during purification via lactonization of $\mathrm{Br}-\mathrm{SA}_{\mathrm{p}}$ or quaternization between the halide and pendent amine moiety in $\mathrm{Cl}-\mathrm{SB}$ and $\mathrm{Cl}-\mathrm{BS}$. Therefore, after quick purification of the obtained dimer halides, the carbon-halogen terminal was immediately converted into a furan-protected maleimide group via the subsequent $\mathrm{S}_{\mathrm{N}} 2$ reaction with the furan-masked maleimide anion. Then, the furan moiety was removed via a retro Diels-Alder reaction, resulting in a series of corresponding maleimide-ended sequence-regulated vinyl oligomonomers (M-SA $\left., \mathrm{M}-\mathrm{A}_{\mathrm{p}} \mathrm{S}, \mathrm{M}-\mathrm{SB}, \mathrm{M}-\mathrm{BS}\right)$ that possess an acid- or base-monomer unit.

Fig. 1 shows the ${ }^{1} \mathrm{H}$ NMR spectra of the maleimide-ended sequence-regulated oligomonomers. All these oligomonomers exhibited characteristic maleimide olefin protons (a) and dimer methine protons (b) adjacent to the nitrogen atom at 6.3-7.7 ppm and 4.3-5.2 ppm, respectively. In addition, intense peaks corresponding to the methyl protons of the $t$-butyl ester (f for $\mathrm{M}-\mathrm{SA} \mathrm{A}_{\mathrm{p}}$ in Fig. $1 \mathrm{~A}$ and $\mathrm{c}$ for $\mathrm{M}-\mathrm{A}_{\mathrm{p}} \mathrm{S}$ in Fig. 1B) and dimethylamino group ( $\mathrm{h}$ for $\mathrm{M}-\mathrm{SB}$ in Fig. $1 \mathrm{C}$ and $\mathrm{e}$ for $\mathrm{M}-\mathrm{BS}$ in Fig. 1D) were observed. The structures were also confirmed by ${ }^{13} \mathrm{C}$ NMR (Fig. S1†). These results indicate the successful synthesis of a series of maleimide-ended sequenceregulated oligomonomers bearing acid- or base-monomer units on the outside or inside of the monomer sequences.

Synthesis of main- and side-chain sequence-regulated vinyl copolymers with acid and base groups via alternating free radical copolymerization with styrene

Free radical alternating copolymerization of a series of maleimide-ended sequence-regulated acid- or base-functionalized oligomonomers and styrene was investigated (Table 1 and Fig. 2). For the radical copolymerization of styrene and oligomonomers with a $t$-butyl acrylate unit $\left(\mathrm{M}-\mathrm{SA}, \mathrm{M}-\mathrm{A}_{\mathrm{p}} \mathrm{S}\right)$ at a $1: 1$ feed ratio in toluene at $60^{\circ} \mathrm{C}$ with AIBN, both styrene and the 


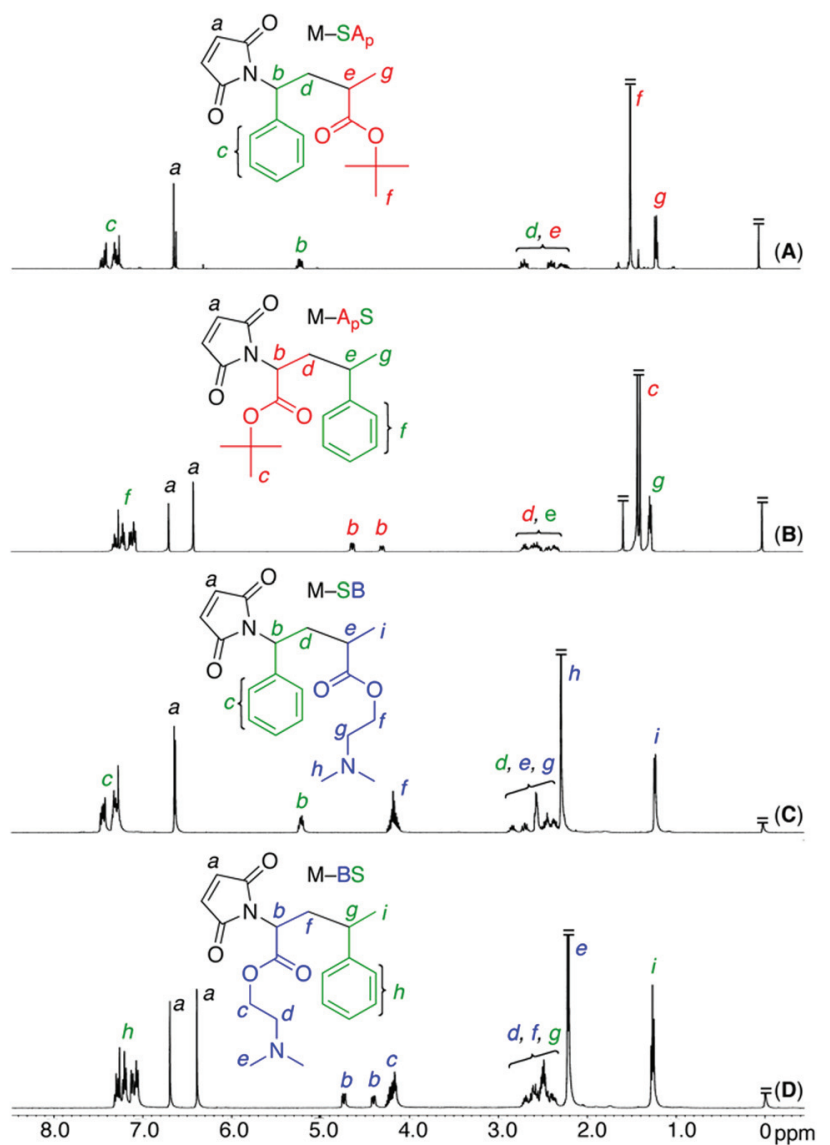

Fig. $1{ }^{1} \mathrm{H}$ NMR spectra $\left(\mathrm{CDCl}_{3}\right.$, r.t.) of a series of maleimide-ended sequence-regulated oligomonomers $\left(M-S A_{p}(A), M-A_{p} S(B), M-S B(C)\right.$, M-BS (D)).

maleimide group were consumed at nearly the same rate to yield copolymers with relatively high molecular weights $\left(M_{\mathrm{n}}>\right.$ $180000)$ similar to the previously reported unfunctionalized maleimide-ended oligomonomers and styrene. ${ }^{17,18}$ However, radical copolymerization of the amine-functionalized oligomonomers with styrene resulted in only low molecular weight polymers $\left(M_{\mathrm{n}}=1000-2000\right)$ in toluene and DMF at $60{ }^{\circ} \mathrm{C}$ due to irreversible chain-transfer reactions caused by the amine moiety despite their consumption at nearly the same rate. However, in a fluorinated alcohol $\left(\mathrm{PhC}\left(\mathrm{CF}_{3}\right)_{2} \mathrm{OH}\right)$ with weak acidity, the alternating radical copolymerization successfully
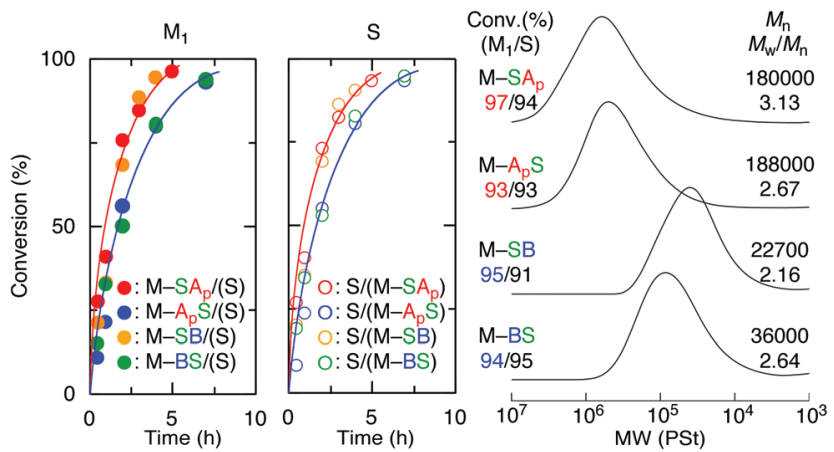

Fig. 2 Alternating free radical copolymerization of sequence-regulated functional maleimide-ended oligomonomer $\left(M_{1}\right)$ and styrene (S). $\left[M_{1}\right]_{0}=$ $[S]_{0}=1.0 \mathrm{M}$. $[A I B N]_{0}=20 \mathrm{mM}$ in toluene at $60^{\circ} \mathrm{C}$ for $\mathrm{M}-\mathrm{SA}_{\mathrm{p}}$ and $\mathrm{M}-\mathrm{A}_{\mathrm{p}} \mathrm{S}$. $[\mathrm{V}-70]_{0}=20 \mathrm{mM}$ in $\mathrm{PhC}\left(\mathrm{CF}_{3}\right)_{2} \mathrm{OH}$ at $20^{\circ} \mathrm{C}$ for $\mathrm{M}-\mathrm{SB}$ and $\mathrm{M}-\mathrm{BS}$.

proceeded at $20^{\circ} \mathrm{C}$ with a low temperature radical azo-initiator (V-70), resulting in alternating copolymers with higher molecular weights $\left(M_{\mathrm{n}}=20000-40000\right) .{ }^{1} \mathrm{H}$ NMR analysis of the resulting copolymers confirmed a 1:1 incorporation of the styrene and oligomonomers into the copolymers, indicating the formation of sequence-regulated alternating main chains.

Hydrolysis of the $t$-butyl ester in poly $\left(\mathrm{M}-\mathrm{SA}_{\mathrm{p}}\right.$-alt-S) and poly $\left(\mathrm{M}-\mathrm{A}_{\mathrm{p}} \mathrm{S}\right.$-alt-S) was conducted using $\mathrm{CF}_{3} \mathrm{COOH}$ in $\mathrm{CHCl}_{3}$ at $20{ }^{\circ} \mathrm{C}$ to convert the ester to carboxylic acid groups. After hydrolysis, the obtained products were purified by precipitation in $n$-hexane and analyzed by ${ }^{1} \mathrm{H}$ NMR. As shown in Fig. S2, $\uparrow$ after hydrolysis, the sharp methyl protons of the $t$-butyl group completely disappeared, which was accompanied by the appearance of broad carboxylic acid signals at approximately $11 \mathrm{ppm}$. Therefore, main- and side-chain sequenceregulated vinyl copolymers with a carboxylic acid group (i.e., poly(M-SA-alt-S) and poly(M-AS-alt-S)) were successfully synthesized.

\section{Effects of monomer sequences on the properties of sequence-} regulated vinyl copolymers with acid and base groups

The effects of the monomer sequences and substituents of the acrylate units on the thermal properties of the sequence-regulated vinyl copolymers were evaluated using differential scanning calorimetry (DSC). All the copolymers are amorphous and exhibit glass transition temperatures $\left(T_{\mathrm{g}}\right)$ between 90 and

Table 1 Alternating radical copolymerization of maleimide-ended functional oligomonomers $\left(M_{1}\right)$ and styrene (S)

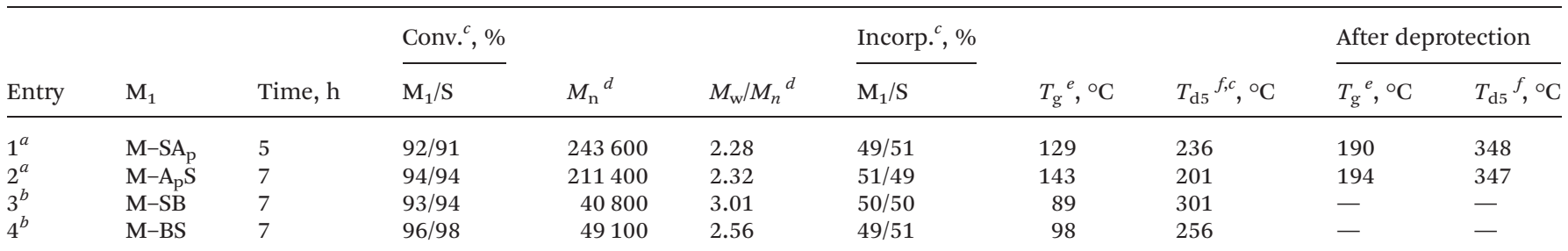

Polymerization conditions: ${ }^{a}\left[\mathrm{M}_{1}\right]_{0} /[\mathrm{S}]_{0} /[\mathrm{AIBN}]_{0}=1000 / 1000 / 20 \mathrm{mM}$ in toluene at $60{ }^{\circ} \mathrm{C} .{ }^{b}\left[\mathrm{M}_{1}\right]_{0} /[\mathrm{S}]_{0} /[\mathrm{V}-70]_{0}=1000 / 1000 / 20 \mathrm{mM}$ in $\mathrm{PhC}(\mathrm{CF})_{2} \mathrm{OH}$ at $20{ }^{\circ} \mathrm{C} .{ }^{c}$ Determined by ${ }^{1} \mathrm{H}$ NMR. ${ }^{d}$ Determined by SEC. ${ }^{e}$ Determined by DSC. ${ }^{f}$ Determined by TGA. 
$200{ }^{\circ} \mathrm{C}$, and these temperatures primarily depend on the substituents of the acrylate moieties with a minor dependence on the sequences (Fig. 3). The $T_{\mathrm{g}}$ of the polymers with the $t \mathrm{BA}$ unit was approximately $130-140{ }^{\circ} \mathrm{C}\left(129{ }^{\circ} \mathrm{C}\right.$ for poly $\left(\mathrm{M}-\mathrm{SA}_{\mathrm{p}}\right.$-alt$\mathrm{S})$ and $143{ }^{\circ} \mathrm{C}$ for poly $\left(\mathrm{M}-\mathrm{A}_{\mathrm{p}} \mathrm{S}\right.$-alt-S $)$ ), and these values increased to $190-195{ }^{\circ} \mathrm{C}$ after deprotection of the tert-butyl group to the acid moiety $\left(190{ }^{\circ} \mathrm{C}\right.$ for poly(M-SA-alt-S) and $194{ }^{\circ} \mathrm{C}$ for poly(M-AS-alt-S)) (Fig. 3A). The higher $T_{\mathrm{g}}$ value of the acid forms may be due to hydrogen bonding between the polymers. However, the polymers with DMAEA exhibited low $T_{\mathrm{g}} \mathrm{S}$ of approximately $90-100{ }^{\circ} \mathrm{C}\left(89^{\circ} \mathrm{C}\right.$ for poly(M-SB-alt-S $)$ and $98{ }^{\circ} \mathrm{C}$ for poly(M-BS-alt-S)) (Fig. 3B) due to the amine-substituted alkyl substituents. Comparing the $T_{\mathrm{g}} \mathrm{s}$ between a pair of isomeric polymers (i.e., poly $\left(\mathrm{M}-\mathrm{SA} \mathrm{p}_{\mathrm{p}}\right.$-alt-S) vs. (poly $\left(\mathrm{M}-\mathrm{A}_{\mathrm{p}} \mathrm{S}\right.$-alt$\mathrm{S})$, poly(M-SA-alt-S) vs. (poly(M-AS-alt-S), and (poly(M-SB-altS) vs. poly(M-BS-alt-S)), all the polymers with outer acrylate units exhibited lower $T_{\mathrm{g}} \mathrm{s}$ than those with inner acrylate units. As previously reported, for copolymers possessing methyl acrylate (MA) and styrene units in their side chains, the $T_{\mathrm{g}} \mathrm{s}$ were not dependent on the sequence for the dimeric units but slightly dependent for the trimeric units. ${ }^{17,18}$ This dependence of $T_{\mathrm{g}}$ on the monomer sequence may be due to bulkier ( $t \mathrm{Bu}$ ) or longer $\left(\mathrm{Me}_{2} \mathrm{NCH}_{2} \mathrm{CH}_{2}\right)$ substituents than the methyl group in $\mathrm{MA}$ and/or polar functional $\left(\mathrm{CO}_{2} \mathrm{H}, \mathrm{NMe}_{2}\right)$ groups.

The degradation behavior was also investigated using thermogravimetric analysis (TGA) (Fig. S3†). For the ester polymers, the degradation occurred via two steps. The first weight loss was approximately $12-14 \%$, which was close to the weight $\%$ of the ester substituents (i.e., $13.2 \%$ for $t \mathrm{Bu}$ and $16.0 \%$ for $\mathrm{Me}_{2} \mathrm{NCH}_{2} \mathrm{CH}_{2}$ ) in the copolymers, indicating that the first decomposition corresponds to loss of the substituents in the ester moieties. In addition, the first decomposition occurred at lower temperatures for the polymers with inner acrylate units (poly $\left(\mathrm{M}-\mathrm{A}_{\mathrm{p}} \mathrm{S}-\right.$ alt-S) and poly(M-BS-alt-S)) but the second decomposition was nearly the same and independent of the monomer sequences. The inductive effects of the nitrogen atoms in the adjacent maleimide unit may affect the decomposition of the ester groups. In contrast, the copolymers with
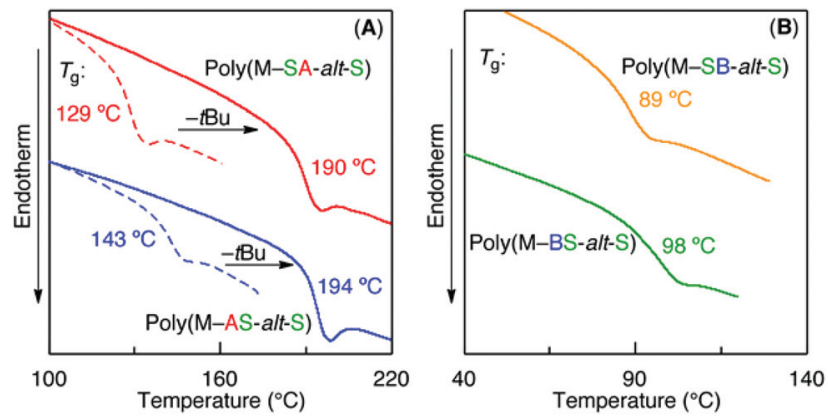

Fig. 3 DSC curves and $T_{\mathrm{g}}$ values of a series of main- and side-chain sequence-regulated functional vinyl copolymers (poly $\left(M_{1}\right.$-alt-S)) obtained in alternating free radical copolymerization of sequence-regulated maleimide-ended oligomonomers and styrene. (A) Dotted lines: poly $\left(M-S A_{p}-a l t-S\right)$ and poly $\left(M-A_{p} S-a l t-S\right)$. Solid lines: poly(M-SA-alt-S) and poly(M-AS-alt-S). (B) poly(M-SB-alt-S) and poly(M-BS-alt-S). acid forms exhibited the same single-step decomposition behaviors, where $T_{\mathrm{d} 5}$ (temperature at $5 \%$ weight loss) was 347-348 ${ }^{\circ} \mathrm{C}$ and nearly independent of the monomer sequences in the side chains.

\section{Alternating RAFT copolymerization of oligomonomers with styrene for molecular weight control}

To precisely determine the monomer sequence effects on the acid-base interactions of the polymers, control of the molecular weight of the sequence-regulated copolymers was investigated by RAFT copolymerization using $S$-cumyl $S^{\prime}$-dithiobenzoate (CDB) as a RAFT agent (Fig. 4 and Table S1†). The RAFT copolymerization proceeded quantitatively at the same consumption rate of oligomonomers and styrene in a fashion similar to the free radical copolymerization, indicating the formation of alternating copolymers. The MWD of the obtained copolymers was narrow but slightly broader for the copolymers with an amine moiety. The molecular weights increased in direct proportion to the monomer conversion even though they were slightly lower than the calculated values based on the assumption that one RAFT agent generates one polymer chain. As we reported previously, the slightly lower molecular weights may be due to the compact hydrodynamic volume of the copolymers with pendent side chains compared to that of polystyrenes as standard samples for the molecular weight calibration. ${ }^{17,18}$ These results indicate that a series of mainand side-chain sequence-regulated vinyl copolymers with an acid or base function and nearly the same controlled chain lengths $\left(\mathrm{DP}_{n} \sim 100\right)$ were successfully synthesized.

\section{Effects of the monomer sequences on the acid and base interactions of the copolymers}

After deprotection of the tert-butyl ester in the copolymers, the acid- and base-functionalized copolymers with controlled molecular weights prepared by RAFT were dissolved in $\mathrm{CHCl}_{3}$. The copolymer solutions were mixed together at the same acid and base concentrations $\left(\left[\mathrm{CO}_{2} \mathrm{H}\right]=\left[\mathrm{NMe}_{2}\right]=0.50 \mathrm{mM}\right)$ and analyzed by dynamic light scattering (DLS) at $20^{\circ} \mathrm{C}$. All the mixtures exhibited the presence of submicron particles, and the size of these particles depended on the functionalized monomer sequences in the side chains (Fig. 5). The mixture containing outer acid units in the side chain contained particles that were $\sim 330 \mathrm{~nm}$ irrespective of the inner or outer base units in the counterpart polymers. However, the inner $\mathrm{CO}_{2} \mathrm{H}$ copolymers exhibited smaller sizes (i.e., 170-200 nm) that were nearly independent of the inner or outer $\mathrm{NMe}_{2}$ group. Therefore, the copolymers with outer acrylic acid units resulted in larger particles with amine-functionalized copolymers, and the positions of the amino groups barely affected the size of the particles.

To further analyze the effects of the monomer sequences on the complexation behaviors, the mixing ratios of the acid and base-functionalized copolymers were gradually varied. Fig. $\mathrm{S} 4 \dagger$ shows the dependence of the particle sizes on the ratio of the acid concentration to total concentration of the acid and base; in this figure, values lower than the middle 

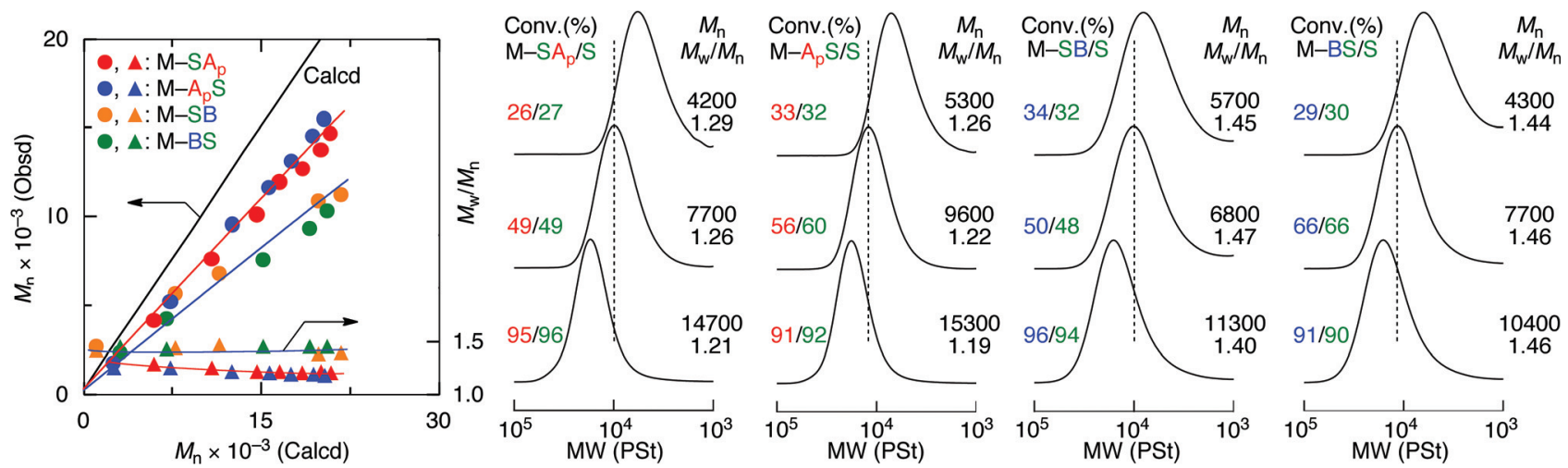

Fig. $4 M_{n}, M_{w} / M_{n}$, and SEC curves for alternating RAFT copolymerization of a series of sequence-regulated functional oligomonomers and styrene in the presence of CDB as a RAFT agent. $\left[\mathrm{M}_{1}\right]_{0}=[\mathrm{S}]_{0}=1.0 \mathrm{M},[\mathrm{CDB}]_{0}=20 \mathrm{mM}$. $[\mathrm{AIBN}]_{0}=20 \mathrm{mM}$ in toluene at $60{ }^{\circ} \mathrm{C}$ for $\mathrm{M}-\mathrm{SA} \mathrm{p}_{\mathrm{p}}$ and $\mathrm{M}-\mathrm{A}_{\mathrm{p}} \mathrm{S}$. $[\mathrm{V}-70]_{0}=$ $20 \mathrm{mM}$ in $\mathrm{PhC}\left(\mathrm{CF}_{3}\right)_{2} \mathrm{OH}$ at $20^{\circ} \mathrm{C}$ for $\mathrm{M}-\mathrm{SB}$ and $\mathrm{M}-\mathrm{BS}$.
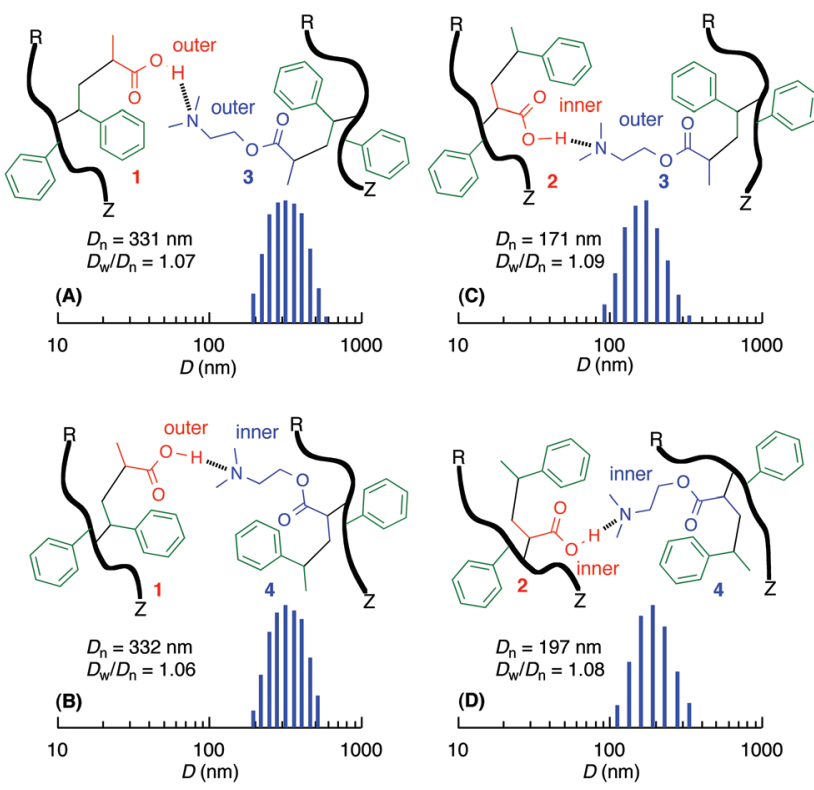

Fig. 5 DLS analysis of mixture of acid- and base-functionalized sequence-regulated vinyl copolymers in $\mathrm{CHCl}_{3}$ at $20^{\circ} \mathrm{C}(0.028$ wt\%): $\left[-\mathrm{CO}_{2} \mathrm{H}\right]=\left[-\mathrm{NMe}_{2}\right]=0.50 \mathrm{mM}$ : (A) 1 and 3 , (B) 1 and 4, (C) 2 and 3, (D) 2 and 4.

point (0.50) indicate excess amine functions, and values higher than 0.50 indicate excess acid functions. The particle size was the smallest at the same concentration for all the mixtures and increased as the concentration of the amine or acid became larger than that of the counterpart. For the copolymers with outer acrylic acid units, the particle size gradually increased with an excess of both base and acid. However, for the inner acrylic acid units, the particle size abruptly increased and ultimately resulted in insoluble products $(>1000 \mathrm{~nm})$ in the presence of excess acid. However, almost no significant dependence on the sequence of the amine parts was observed.

To investigate the interactions between the acid and base groups in the copolymers, the association constants $(K)$ between the acid or base groups and the complimentary model compounds $\left(\mathrm{Me}_{2} \mathrm{NCH}_{2} \mathrm{CH}_{2} \mathrm{OC}(\mathrm{O}) \mathrm{CH}_{3}\right.$ (5) or $\mathrm{CH}_{3} \mathrm{CO}_{2} \mathrm{H}$ (6)) were analyzed by ${ }^{1} \mathrm{H}$ NMR titration (Fig. S5†) because a mixture of the complimentary polymers resulted in precipitation in some cases. The $K$ value of 5 for the inner acrylic acid unit (2) was higher $\left(94.1 \mathrm{M}^{-1}\right)$ than that for the outer one (1) $\left(20.7 \mathrm{M}^{-1}\right)$ under the same conditions. This result may be due to differences in the monomer sequence or the inductive effect of the adjacent imide group. The latter possibility was indicated by the larger $K$ value $\left(141.8 \mathrm{M}^{-1}\right)$ of 5 for the model carboxylic acid with the adjacent imide group (7) compared to that $\left(17.4 \mathrm{M}^{-1}\right)$ for $\mathrm{CH}_{3} \mathrm{CO}_{2} \mathrm{H}(6)$. However, the $K$ values of 6 for the outer (3) $\left(19.8 \mathrm{M}^{-1}\right)$ or inner (4) $\left(20.0 \mathrm{M}^{-1}\right)$ DMAEA unit were nearly the same and comparable to that of the model DMAE compound (5) $\left(17.4 \mathrm{M}^{-1}\right)$. Therefore, the acid-base interactions between the copolymers were affected by the sequences of the functional monomer units in the sequenceregulated vinyl copolymers.

\section{Conclusions}

A series of maleimide-ended sequence-regulated oligomonomers possessing a carboxylic acid- or amine-functionalized vinyl monomer unit were successfully prepared by ATRA followed by the introduction of a maleimide group at the chain end. The maleimide-ended oligomonomers underwent alternating radical copolymerization with styrene to afford mainand side-chain sequence-regulated vinyl copolymers with sequenced acid- and base functions in the side chains. The polymers with inner functionalized monomer units in the side chains exhibited slightly higher $T_{\mathrm{g}} \mathrm{s}$ and lower $T_{\mathrm{d} 5} \mathrm{~S}$ than those of the outer ones. A mixture of acid- and base-functionalized polymers resulted in submicron particles due to acid-base interactions, and the size was affected by the carboxylic acid monomer sequences but not by the amine sequences. This study revealed that the sequence of the functionalized monomer units in vinyl copolymers affects the polymer properties and aggregation behaviors between polymer chains, 
and these insights will lead to understanding and developing functional materials based on monomer sequence control.

\section{Experimental section}

\section{Materials}

Styrene (S) (Kishida, 99.5\%), tert-butyl acrylate ( $t \mathrm{BA})$ (Tokyo Kasei, $>98 \%$ ), 2-(dimethylamino)ethyl acrylate (DMAEA) (Tokyo Kasei, >97\%), triethylamine (Tokyo Kasei, >99\%), 1-phenylethylchloride (Cl-S) (Tokyo Kasei, >97\%), 1-phenylethylbromide (Br-S) (Tokyo Kasei, >95\%), and $N, N, N^{\prime}, N^{\prime \prime}, N^{\prime \prime}$ pentamethyldiethylenetriamine (PMDETA) (Aldrich, >99\%) were distilled over calcium hydride under reduced pressure before use. tert-Butyl $\alpha$-chloropropionate $\left(\mathrm{A}_{\mathrm{p}}-\mathrm{Cl}\right)$ (Wako, 97\%), 2-chloropropionyl chloride (Tokyo Kasei, >95\%), and 2-dimethylaminoethanol (Tokyo Kasei, >99\%) were used as received. CuBr (Aldrich, 99.999\%), $\left[\mathrm{Cp}^{*} \mathrm{Ru}\left(\mu_{3}-\mathrm{Cl}\right)\right]_{4}$ (Aldrich, 95\%), and triphenylphosphine (Aldrich, 99\%) were used as received and treated in a glove box (MBRAUN LABmaster sp) under an oxygen- and moisture-free argon atmosphere $\left(\mathrm{O}_{2}\right.$, $<1 \mathrm{ppm}$ ). Toluene (Kanto, >99.5\%; $\mathrm{H}_{2} \mathrm{O}<10 \mathrm{ppm}$ ) was dried and deoxygenized by passage through columns of Glass Contour Solvent Systems before use. Furan-masked-maleimide was synthesized according to the literature. ${ }^{17} \alpha, \alpha$-Azobisisobutyronitrile (AIBN) (Kishida, >99\%) was purified by recrystallization from methanol. 2,2'-Azobis(4-methoxy-2,4dimethylvaleronitrile) (V-70) (Wako, 95\%) was purified by washing with acetone at $-15^{\circ} \mathrm{C}$ and was evaporated to dryness under reduced pressure. Cumyl dithiobenzoate (CDB) was synthesized according to the literature. ${ }^{59-61}$

\section{Synthesis of $\mathbf{M}-\mathrm{SA}_{\mathbf{p}}$}

A maleimide-ended styrene-tert-butyl acrylate oligomonomer $\left(\mathrm{M}-\mathrm{SA}_{\mathrm{p}}\right)$ was synthesized by copper-catalyzed ATRA followed by $\mathrm{S}_{\mathrm{N}} 2$ and retro Diels-Alder reactions as follows. CuBr $(0.77 \mathrm{~g}$, $5.4 \mathrm{mmol})$, PMDETA $(1.0 \mathrm{ml}, 5.4 \mathrm{mmol})$, toluene $(3.0 \mathrm{~mL})$, styrene $(25 \mathrm{~mL}, 22 \mathrm{mmol})$, and tert-butyl $\alpha$-bromopropionate $(79 \mathrm{~mL}, 480 \mathrm{mmol}$ ) were placed in a $200 \mathrm{~mL}$ round-bottomed flask at room temperature. The flask was put into an oil bath at $60{ }^{\circ} \mathrm{C}$ under vigorous stirring. The styrene conversion was calculated from the vinyl group of the residual styrene measured by ${ }^{1} \mathrm{H}$ NMR. After $3 \mathrm{~h}$, the styrene conversion reached $71 \%$ to from the $1: 1$ adduct $\left(\mathrm{Br}-\mathrm{SA}_{\mathrm{p}} ; 65 \%\right)$. The reaction mixture was passed through a silica gel (Silica Gel $60 \mathrm{~N}$, Kanto) column eluted with $n$-hexane/ethyl acetate (6/4) to remove the residual copper catalyst. After evaporation of the solvents, the products were roughly distilled to yield $\mathrm{Br}-\mathrm{SA}_{\mathrm{p}}$ (44 g, purity $>80 \%$ ).

To a DMF solution $(150 \mathrm{~mL})$ of furan-masked maleimide $(24 \mathrm{~g}, 166 \mathrm{mmol})$ and $\mathrm{K}_{2} \mathrm{CO}_{3}(24 \mathrm{~g}, 190 \mathrm{mmol})$, crude $\mathrm{Br}-\mathrm{SA}_{\mathrm{p}}$ ( $44 \mathrm{~g}, 120 \mathrm{mmol}$ ) was added at room temperature. The mixture was heated at $50{ }^{\circ} \mathrm{C}$ and kept stirred for $12 \mathrm{~h}$. After the $\mathrm{S}_{\mathrm{N}} 2$ reaction, the mixture was washed with water. The solvents of the organic layer were removed by evaporation. The crude product was purified by a silica-gel column eluted with $n$-hexane/ethyl acetate (9/1-7/3) and then evaporated under vacuum to yield the furan-masked maleimide-ended oligomonomer of $\mathrm{S}$ and $\mathrm{A}_{\mathrm{p}}$ units $(22 \mathrm{~g}, 57 \mathrm{mmol})$. The furanmasked maleimide was diluted with toluene and stirred for $12 \mathrm{~h}$ at $115^{\circ} \mathrm{C}$ for the retro Diels-Alder reaction. After evaporation of volatiles, the crude product was purified by column chromatography (Silica Gel 60N, $n$-hexane/ethyl acetate $=7 / 3$ ) to yield pure $\mathrm{M}-\mathrm{SA}_{\mathrm{p}}$ as a colorless viscous oil (total yield $13 \%$, purity $>98 \%)$. ${ }^{1} \mathrm{H}$ NMR $\left(\mathrm{CDCl}_{3}\right.$, r.t.): $\delta 1.12-1.16$ (dd, $\mathrm{CH}_{3}-\mathrm{CH}_{2}$ ), 1.42-1.46 (d, $\left.\left(\mathrm{CH}_{3}\right)_{3} \mathrm{C}-\mathrm{O}\right), \quad 2.10-2.71$ (m, 3H), $5.11-5.25$ $(\mathrm{m}, \mathrm{CHN}), 6.51-6.65(\mathrm{~d}, \mathrm{CH}=\mathrm{CH}), 7.16-7.49(\mathrm{~m}, 5 \mathrm{H})$.

\section{Synthesis of $\mathbf{M}-\mathbf{A}_{\mathbf{p}} \mathrm{S}$}

A maleimide-ended tert-butyl acrylate-styrene oligomonomer $\left(\mathrm{M}-\mathrm{A}_{\mathrm{p}} \mathrm{S}\right)$ was synthesized by ruthenium-catalyzed ATRA followed by $\mathrm{S}_{\mathrm{N}} 2$ and retro Diels-Alder reactions as follows. $\left[\mathrm{Cp}{ }^{*} \mathrm{Ru}\left(\mu_{3}-\mathrm{Cl}\right)\right]_{4}(0.50 \mathrm{~g}, 0.50 \mathrm{mmol}), \mathrm{PPh}_{3}(1.0 \mathrm{~g}, 4.0 \mathrm{mmol})$, and toluene $(5.0 \mathrm{~mL})$ were placed in a $300 \mathrm{~mL}$ round-bottomed flask at room temperature. The reaction mixture was kept stirred for $12 \mathrm{~h}$ at $80{ }^{\circ} \mathrm{C}$, and then $t$ BA $(109 \mathrm{~mL}, 750 \mathrm{mmol})$, $\mathrm{Br}-\mathrm{S}(136 \mathrm{~mL}, 760 \mathrm{mmol})$, and $\mathrm{Et}_{3} \mathrm{~N}(0.70 \mathrm{ml}, 5.0 \mathrm{mmol})$ were added at room temperature. The flask was put into an oil bath at $60{ }^{\circ} \mathrm{C}$ under vigorous stirring. The $t \mathrm{BA}$ conversion was calculated from the vinyl group of the residual $t \mathrm{BA}$ measured by ${ }^{1} \mathrm{H}$ NMR. After $65 \mathrm{~h}$, the $t \mathrm{BA}$ conversion reached $26 \%$ to form the $1: 1$ adduct $\left(B r-A_{p} S ; 19 \%\right)$. The reaction mixture was passed through a silica gel (Silica Gel 60N, Kanto) column with $n$-hexane/ethyl acetate (7/3) to remove the ruthenium catalyst. After evaporation of the solvents, the products were roughly distilled to yield $\mathrm{Br}-\mathrm{A}_{\mathrm{p}} \mathrm{S}$ (58 g, purity $>66 \%$ ).

To a DMF solution (190 $\mathrm{mL})$ of furan-masked maleimide (28 g, $170 \mathrm{mmol})$ and $\mathrm{K}_{2} \mathrm{CO}_{3}(28 \mathrm{~g}, 200 \mathrm{mmol})$ crude $\mathrm{Br}-\mathrm{A}_{\mathrm{p}} \mathrm{S}$ $(58 \mathrm{~g}, 126 \mathrm{mmol})$ was added at room temperature. The reaction mixture was heated at $50{ }^{\circ} \mathrm{C}$ and kept stirred for $12 \mathrm{~h}$. After the $\mathrm{S}_{\mathrm{N}} 2$ reaction, the mixture was washed with water. The organic layer was evaporated to remove the solvents. The crude product was purified by a silica-gel column eluted with $n$-hexane/ethyl acetate (9/1-7/3) and then evaporated under vacuum to obtain the furan-masked maleimide-ended oligomonomer of $A_{p}$ and $S$ units (26 g, $66 \mathrm{mmol}$ ). The furan-masked maleimide was diluted with toluene and stirred for $12 \mathrm{~h}$ at $115{ }^{\circ} \mathrm{C}$ for the retro Diels-Alder reaction. After evaporation of volatiles, the crude product was purified by column chromatography (Silica Gel $60 \mathrm{~N}, n$-hexane/ethyl acetate $=7 / 3$ ) and by recrystallization to yield pure $\mathrm{M}-\mathrm{A}_{\mathrm{p}} \mathrm{S}$ as colorless crystals (total yield $5 \%$, purity $>99 \%) .{ }^{1} \mathrm{H} \mathrm{NMR}\left(\mathrm{CDCl}_{3}\right.$, r.t.): $\delta 1.23-1.29$ (dd, $\left.\mathrm{CH}_{3}-\mathrm{CH}_{2}\right), 1.36-1.42\left(\mathrm{~d},\left(\mathrm{CH}_{3}\right)_{3} \mathrm{C}-\mathrm{O}\right), 2.27-2.76(\mathrm{~m}, 3 \mathrm{H})$, 4.22-4.32, 4.59-4.66 (m, $\mathrm{CH}-\mathrm{N}), 6.41,6.69(\mathrm{~d}, \mathrm{CH}=\mathrm{CH})$, 7.05-7.35 (m, 5H).

\section{Synthesis of M-SB}

A maleimide-terminated styrene-2-(dimethylamino)ethyl acrylate oligomonomer (M-SB) was synthesized by ATRA followed by $\mathrm{S}_{\mathrm{N}} 2$ and retro Diels-Alder reactions as follows. 2-(Dimethylamino)ethyl $\alpha$-chloropropionate was synthesized from 2-chloropropionyl chloride and 2-dimethylaminoethanol. 
2-Chloropropionyl chloride (82 $\mathrm{mL}, 880 \mathrm{mmol}$ ) was added dropwise with stirring to a mixture of 2-dimethylaminoethanol (81 $\mathrm{mL}, 800 \mathrm{mmol})$ and triethylamine $(123 \mathrm{~mL}, 840 \mathrm{mmol})$ in dry THF $(340 \mathrm{~mL})$ at $0{ }^{\circ} \mathrm{C}$. The reaction mixture was stirred for $5 \mathrm{~h}$ at $0{ }^{\circ} \mathrm{C}$ and then for $5 \mathrm{~h}$ at room temperature. After dilution with $n$-hexane, the mixture was washed with the aqueous solution of $\mathrm{NaOH}$ and then $\mathrm{NaCl}$ followed by evaporation to remove the solvents. The product was distilled under reduced pressure to give pure 2-(dimethylamino)ethyl $\alpha$-chloropropionate (58 g, $320 \mathrm{mmol}, 40 \%)$.

Then, ruthenium-catalyzed ATRA of styrene to the obtained product was conducted. $\left[\mathrm{Cp}^{*} \mathrm{Ru}\left(\mu_{3}-\mathrm{Cl}\right)\right]_{4}(0.11 \mathrm{~g}$, $0.10 \mathrm{mmol}), \mathrm{PPh}_{3}(0.21 \mathrm{~g}, 0.80 \mathrm{mmol})$, and toluene $(5.0 \mathrm{~mL})$ were placed in a $300 \mathrm{~mL}$ round-bottomed flask at room temperature. The reaction mixture was kept stirred for $12 \mathrm{~h}$ at $80{ }^{\circ} \mathrm{C}$, and then styrene $(11 \mathrm{~mL}, 93 \mathrm{mmol}), 2$-(dimethylamino)ethyl $\alpha$-chloropropionate $\left(35 \mathrm{~mL}, 254 \mathrm{mmol}\right.$ ), and $\mathrm{Et}_{3} \mathrm{~N}$ $(0.15 \mathrm{ml}, 3.2 \mathrm{mmol})$ were added at room temperature. The flask was put into an oil bath at $60{ }^{\circ} \mathrm{C}$ under vigorous stirring. The styrene conversion was calculated from the vinyl group of the residual styrene measured by ${ }^{1} \mathrm{H}$ NMR. After $18 \mathrm{~h}$, the styrene conversion reached $81 \%$ to form the $1: 1$ adduct (Cl-SB; 75\%). The reaction mixture was passed through a silica gel (Silica Gel 60N, Kanto) column with diethyl ether to remove the ruthenium catalyst. After evaporation of the solvents, the products were roughly distilled to yield Cl-SB (17 g, $58 \mathrm{mmol}, 63 \%)$.

To a DMF solution (91 mL) of furan-masked maleimide (9.2 g, $56 \mathrm{mmol})$ and $\mathrm{K}_{2} \mathrm{CO}_{3}(9.2 \mathrm{~g}, 67 \mathrm{mmol})$, crude $\mathrm{Cl}-\mathrm{SB}$ $(17 \mathrm{~g}, 58 \mathrm{mmol})$ was added at room temperature. The reaction mixture was heated at $65^{\circ} \mathrm{C}$ and kept stirred for $90 \mathrm{~h}$. After the $\mathrm{S}_{\mathrm{N}} 2$ reaction, the mixture was washed with water. The solvents of the organic layer were removed by evaporation. The crude product was purified by a silica gel column eluted with acetone and then evaporated under vacuum to yield the furanmasked maleimide-ended oligomonomer of S and B units (14 g, $34 \mathrm{mmol}$ ). The furan-masked maleimide was diluted with toluene and stirred for $11 \mathrm{~h}$ at $115{ }^{\circ} \mathrm{C}$ for the retro DielsAlder reaction. After evaporation of volatiles, the crude product was purified by column chromatography (Silica Gel 60N, diethyl ether/acetone/ $\mathrm{Et}_{3} \mathrm{~N}=9.0 / 0.5 / 0.5$ ) to yield pure $\mathrm{M}-\mathrm{SB}$ as a clear and viscous oil (total yield $7 \%$, purity $>99 \%$ ). ${ }^{1} \mathrm{H}$ NMR $\left(\mathrm{CDCl}_{3}\right.$, r.t.): $\delta 1.22-1.30$ (dd, $\left.\mathrm{CH}_{3}-\mathrm{CH}_{2}\right), 2.10-2.75(\mathrm{~m}, 5 \mathrm{H})$, 2.19-2.23 (d, $\left.\left(\mathrm{CH}_{3}\right)_{2}-\mathrm{N}\right), 4.10-4.28$ (m, $\left.\mathrm{CH}_{2}-\mathrm{O}\right), 4.36-4.44$, 4.69-4.78 (m, $\mathrm{CH}-\mathrm{N}), 6.39,6.69$ (d, $\mathrm{CH}=\mathrm{CH}), \quad 6.99-7.34$ $(\mathrm{m}, 5 \mathrm{H})$.

\section{Synthesis of M-BS}

A maleimide-ended 2-(dimethylamino)ethyl acrylate-styrene oligomonomer (M-BS) was synthesized by ruthenium-catalyzed ATRA followed by $\mathrm{S}_{\mathrm{N}} 2$ and retro Diels-Alder reactions as follows. $\left[\mathrm{Cp}{ }^{*} \mathrm{Ru}\left(\mu_{3}-\mathrm{Cl}\right)\right]_{4}(0.6 \mathrm{~g}, 0.50 \mathrm{mmol}), \mathrm{PPh}_{3}(1.1 \mathrm{~g}$, $4.0 \mathrm{mmol})$, and toluene $(10 \mathrm{~mL})$ were placed in a $300 \mathrm{~mL}$ round-bottomed flask at room temperature. The reaction mixture was kept stirred for $12 \mathrm{~h}$ at $80^{\circ} \mathrm{C}$, and then DMAEA (76 mL, $500 \mathrm{mmol}), \mathrm{Cl}-\mathrm{S}(163 \mathrm{~mL}, 1230 \mathrm{mmol})$, and $\mathrm{Et}_{3} \mathrm{~N}$
$(0.7 \mathrm{ml}, 8.0 \mathrm{mmol})$ were added at room temperature. The flask was immersed in an oil bath maintained at $60{ }^{\circ} \mathrm{C}$ under vigorous stirring. The DMAEA conversion was determined from the vinyl group of the residual DMAEA measured by ${ }^{1} \mathrm{H}$ NMR. After $20 \mathrm{~h}$, the DMAEA conversion reached 51\% to form the $1: 1$ adduct (Cl-BS; $12 \%$ ). To remove the ruthenium catalyst, the reaction mixture was drained through a silica gel (Silica Gel 60N, Kanto) column eluted with diethyl ether. After evaporation of the solvents, the products were roughly distilled to yield Cl-BS (14 g, $48 \mathrm{mmol}, 10 \%)$.

To DMF solution (63 mL) of furan-masked maleimide $(6.3 \mathrm{~g}, 38 \mathrm{mmol})$ and $\mathrm{K}_{2} \mathrm{CO}_{3}(6.3 \mathrm{~g}, 47 \mathrm{mmol})$ was added crude $\mathrm{Cl}-\mathrm{BS}(11 \mathrm{~g}, 46 \mathrm{mmol})$ at room temperature. The mixture was heated at $65{ }^{\circ} \mathrm{C}$ and kept stirred for $15 \mathrm{~h}$. After the $\mathrm{S}_{\mathrm{N}} 2$ reaction, the mixture was washed with water. The organic layer was evaporated to remove the solvents. The crude product was purified by a silica gel column eluted with acetone and then evaporated under vacuum to yield the furan-masked maleimideended oligomonomer of B and S units (11 g, $28 \mathrm{mmol})$. The furan-masked maleimide was diluted with toluene and stirred for $10 \mathrm{~h}$ at $115{ }^{\circ} \mathrm{C}$ for the retro Diels-Alder reaction. After evaporation of volatiles, the crude product was purified by column chromatography (Silica Gel $60 \mathrm{~N}$, diethyl ether/acetone/Et ${ }_{3} \mathrm{~N}=$ 9.0/0.5/0.5) to yield pure M-BS as clear and viscous oil (total yield 7\%, purity $>99 \%) .{ }^{1} \mathrm{H}$ NMR $\left(\mathrm{CDCl}_{3}\right.$, r.t.): $\delta 1.19-1.24$ (dd, $\left.\mathrm{CH}_{3}-\mathrm{CH}_{2}\right), 2.18-2.75(\mathrm{~m}, 5 \mathrm{H}), 2.26-2.89\left(\mathrm{~d}, \quad\left(\mathrm{CH}_{3}\right)_{2}-\mathrm{N}\right)$, 4.08-4.25 (m, $\left.\mathrm{CH}_{2}-\mathrm{O}\right), 5.15-5.25$ (m, $\left.\mathrm{CH}-\mathrm{N}\right), 6.61-6.64$ (d, $\mathrm{C} H=\mathrm{C} H), 7.18-7.49(\mathrm{~m}, 5 \mathrm{H})$.

\section{$1: 1$ alternating free radical copolymerization}

1:1 alternating free radical copolymerization was conducted under dry nitrogen in sealed glass tubes by the syringe technique. A representative example for the polymerization procedure is provided below. Toluene, $\mathrm{M}-\mathrm{SA}_{\mathrm{p}}(0.65 \mathrm{~g}, 2.0 \mathrm{mmol})$, styrene $(0.23 \mathrm{~mL}, 2.0 \mathrm{mmol})$, and toluene solution of AIBN $(0.20 \mathrm{~mL}$ of $200 \mathrm{mM}$ solution, $0.04 \mathrm{mmol})$ were placed in a $25 \mathrm{~mL}$ round-bottomed flask at room temperature. The total volume of the reaction mixture was $3.0 \mathrm{~mL}$. Instantly after mixing, aliquots ( $0.2 \mathrm{~mL}$ each) of the solution were divided by syringe into baked glass tubes, which were then sealed by flame under a nitrogen atmosphere. The tubes were put into thermostatic oil bath at $60^{\circ} \mathrm{C}$. In certain intervals, the reaction mixture was cooled to $-78^{\circ} \mathrm{C}$ to terminate the polymerization. Conversions of oligomonomers and styrene were determined from the residual $\mathrm{M}-\mathrm{SA}_{\mathrm{p}}$ and styrene of concentrations, respectively, by ${ }^{1} \mathrm{H}$ NMR. The quenched reaction solutions were evaporated dryness to yield the product polymers $(5 \mathrm{~h}$, $92 \%$ for $\mathrm{M}-\mathrm{SA}$ p and $91 \%$ for styrene, $M_{\mathrm{n}}=243600, M_{\mathrm{w}} / M_{\mathrm{n}}=$ 2.28).

\section{1:1 alternating RAFT copolymerization}

RAFT copolymerization was conducted under dry nitrogen in sealed glass tubes by syringe technique. A representative example for the copolymerization with $\mathrm{CDB}$ in the presence of AIBN in toluene is provided below. Toluene, M-SA $(0.65 \mathrm{~g}$, $2.0 \mathrm{mmol})$, styrene $(0.23 \mathrm{~mL}, 2.0 \mathrm{mmol})$, toluene solution of 
AIBN $(0.10 \mathrm{~mL}$ of $100 \mathrm{mM}$ solution, $0.01 \mathrm{mmol})$, and another toluene solution of $\mathrm{CDB}(0.49 \mathrm{~mL}$ of $408 \mathrm{mM}$ solution, $0.04 \mathrm{mmol}$ ) were placed in a $50 \mathrm{~mL}$ flask at room temperature. The total volume of the reaction mixture was $2.0 \mathrm{~mL}$. Instantly after mixing, aliquots ( $0.4 \mathrm{~mL}$ each) of the solution were divided by syringe into baked glass tubes, which were then sealed by flame under a nitrogen atmosphere. The tubes were put into a thermostatic oil bath at $60{ }^{\circ} \mathrm{C}$. In certain intervals, the reaction mixtures were cooled to $-78{ }^{\circ} \mathrm{C}$ to terminate the polymerization. Conversion of oligomonomers and styrene were determined from the residual $\mathbf{M}-\mathrm{SA}_{\mathrm{p}}$ and styrene of concentrations, respectively, by ${ }^{1} \mathrm{H}$ NMR. The quenched reaction solutions were evaporated to dryness to give the product polymers $\left(24 \mathrm{~h}, 95 \%\right.$ for $\mathrm{M}-\mathrm{SA}_{\mathrm{p}}$ and $96 \%$ for styrene, $M_{\mathrm{n}}=15900$, $\left.M_{\mathrm{w}} / M_{\mathrm{n}}=1.16\right)$.

\section{Hydrolysis of tert-butyl ester}

Hydrolysis of the tert-butyl ester of the obtained polymers was conducted using $\mathrm{CF}_{3} \mathrm{COOH}$ as follows. The polymer with the tert-butyl ester $(400 \mathrm{mg})$ was dissolved in $\mathrm{CHCl}_{3}(12 \mathrm{~mL})$, and then $\mathrm{CF}_{3} \mathrm{COOH}(6 \mathrm{~mL})$ was added dropwise with vigorous stirring at room temperature for $12 \mathrm{~h}$. The reaction mixture was evaporated to dryness and the product dissolved in THF, and precipitated from $n$-hexane to give the polymer with carboxylic acid as a colorless powder.

\section{Measurement}

${ }^{1} \mathrm{H}$ NMR spectra were measured in $\mathrm{CDCl}_{3}$ at room temperature on a JEOL ESC-400 spectrometer, operating at $400 \mathrm{MHz}$. MALDI-TOF-MS spectra were recorded on a Shimadzu AXIMA-CFR Plus mass spectrometer (linear mode) with trans2-[3-(4-tert-buthylpheyl)-2-methyl-2-propenylidene]-malononitrile (DCTB) as the ionizing matrix and sodium trifluoroacetate as the ion source. The number-average molecular weight $\left(M_{\mathrm{n}}\right)$ and molecular weight distribution $\left(M_{\mathrm{w}} / M_{\mathrm{n}}\right)$ of the product polymers were determined by SEC in THF at $40{ }^{\circ} \mathrm{C}$ on two polystyrene gel columns [Tosoh Multipore $\mathrm{H}_{\mathrm{XL}}-\mathrm{M}(7.8 \mathrm{~mm}$ i.d. $\times$

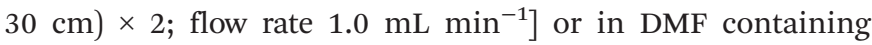
$100 \mathrm{mM} \mathrm{LiCl}$ at $40{ }^{\circ} \mathrm{C}$ on two polystyrene gel columns [Shodex K-805L (pore size: $20-1000 \AA$; $30 \mathrm{~cm} \times 8.0 \mathrm{~mm}$ i.d.), flow rate $1.0 \mathrm{~mL} \mathrm{~min}^{-1}$ ] connected to a JASCO PU-2080 precision pump and a JASCO RI-2031 detector. The columns were calibrated against standard polystyrene samples (Varian; $M_{\mathrm{p}}=$ 580-3 $\left.053000, M_{\mathrm{w}} / M_{\mathrm{n}}=1.02-1.23\right)$. The glass transition temperature $\left(T_{\mathrm{g}}\right)$ of the polymers was recorded on a Q200 differential scanning calorimeter (TA Instruments Inc.). Samples were first heated to $220{ }^{\circ} \mathrm{C}$ at $10^{\circ} \mathrm{C} \mathrm{min}^{-1}$, equilibrated at this temperature for $10 \mathrm{~min}$, and cooled to $-50{ }^{\circ} \mathrm{C}$ at $10{ }^{\circ} \mathrm{C} \mathrm{min}^{-1}$. After being held at this temperature for $5 \mathrm{~min}$, the samples were then reheated to $220{ }^{\circ} \mathrm{C}$ at $10^{\circ} \mathrm{C} \mathrm{min}^{-1}$. All $T_{\mathrm{g}}$ values were thus obtained from the second scan. Thermogravimetric analyses (TGA) were performed on a Q500 system (TA Instruments Inc.) at $5{ }^{\circ} \mathrm{C} \min ^{-1}$ under a $\mathrm{N}_{2}$ gas flow. DLS measurements were performed on a DLS-8000DL (Otuska Electronics) with a $632.8 \mathrm{~nm} \mathrm{He}-\mathrm{Ne}$ laser, where the scattering angle was fixed at $90^{\circ}$.

\section{Acknowledgements}

This work was supported in part by a Grant-in-Aid for Scientific Research (A) (no. 15H02181) for M. K. by the Japan Society for the Promotion of Science and Program for Leading Graduate Schools "Integrative Graduate Education and Research Program in Green Natural Sciences”.

\section{Notes and references}

1 J.-F. Lutz, Polym. Chem., 2010, 1, 55-62.

2 J.-F. Lutz, M. Ouchi, D. R. Liu and M. Sawamoto, Science, 2013, 341, 1238149.

3 J.-F. Lutz, Acc. Chem. Res., 2013, 46, 2696-2705.

4 ACS Symposium Series 1170, Sequence-Controlled Polymers: Synthesis, Self-Assembly, and Properties, ed. J.-F. Lutz, T. Meyer, M. Ouchi and M. Sawamoto, American Chemical Society, Washington DC, 2014.

5 Control of Polymer Sequences, M. Kamigaito and K. Satoh, in McGraw-Hill Yearbook of Science and Technology 2015, McGraw-Hill, New York, 2015, http://www.accessscience. com/content/control-of-polymer-sequences/YB150543.

6 J. M. G. Cowie, Alternating Copolymers, Plenum Press, New York, 1985.

7 C. Hagiopol, Copolymerization: Toward a Systematic Approach, Kluwer Academic/Plenum Publishers, New York, 1999.

8 S. Pfeifer and J.-F. Lutz, J. Am. Chem. Soc., 2007, 129, 95429543.

9 M. Zamfir and J.-F. Lutz, Nat. Commun., 2012, 3, 1138.

10 J.-F. Lutz, B. V. K. J. Schmidt and S. Pfeifer, Macromol. Rapid Commun., 2011, 32, 127-135.

11 S. Srichan, H. Mutlu and J.-F. Lutz, Eur. Polym. J., 2015, 62, 338-346.

12 K. Satoh, M. Matsuda, K. Nagai and M. Kamigaito, J. Am. Chem. Soc., 2010, 132, 10003-10005.

13 M. Matsuda, K. Satoh and M. Kamigaito, J. Polym. Sci., Part A: Polym. Chem., 2013, 51, 1774-1785.

14 M. Matsuda, K. Satoh and M. Kamigaito, Macromolecules, 2013, 46, 5473-5482.

15 K. Satoh, Polym. J., 2015, 47, 527-536.

16 T. Soejima, K. Satoh and M. Kamigaito, ACS Symp. Ser., 2014, 1170, 189-200.

17 T. Soejima, K. Satoh and M. Kamigaito, ACS Macro Lett., 2015, 4, 745-749.

18 T. Soejima, K. Satoh and M. Kamigaito, J. Am. Chem. Soc., 2016, 138, 944-954.

19 A. Kanazawa and S. Aoshima, ACS Macro Lett., 2015, 4, 783-787.

20 L. R. Hutchings, P. P. Brooks, D. Parker, J. A. Mosely and S. Sevinc, Macromolecules, 2015, 48, 610-628.

21 K. Takemoto and Y. Inaki, Adv. Polym. Sci., 1981, 41, 1-51.

22 Y. Y. Tan, Prog. Polym. Sci., 1994, 19, 561-588.

23 A. Khan, D. M. Haddleton, M. J. Hannon, D. Kukulj and A. Marsh, Macromolecules, 1999, 32, 6560-6564.

24 M. Garcia, K. Kempe, D. M. Haddleton, A. Khan and A. Marsh, Polym. Chem., 2015, 6, 1944-1951. 
25 S. Ida, T. Terashima, M. Ouchi and M. Sawamoto, J. Am. Chem. Soc., 2009, 131, 10808-10809.

26 S. Ida, T. Terashima, M. Ouchi and M. Sawamoto, J. Am. Chem. Soc., 2010, 132, 14748-14750.

27 S. Ida, M. Ouchi and M. Sawamoto, Macromol. Rapid Commun., 2011, 32, 209-214.

28 Y. Hibi, S. Tokuoka, T. Terashima, M. Ouchi and M. Sawamoto, Polym. Chem., 2011, 2, 341-347.

29 Y. Hibi, M. Ouchi and M. Sawamoto, Angew. Chem., Int. Ed., 2011, 50, 7434-7437.

30 R. McHale, J. P. Peterson, P. B. Zetterlund and R. K. O'Reilly, Nat. Chem., 2012, 4, 491-497.

31 T. Uemura, S. Mochizuki and S. Kitagawa, ACS Macro Lett., 2015, 4, 788-791.

32 F. S. Bates, M. A. Hillmyer, T. P. Lodge, C. M. Bates, K. T. Delaney and G. H. Fredrickson, Science, 2012, 336, 434-440.

33 A. H. Soeriyadi, C. Boyer, F. Nyström, P. B. Zetterlund and M. R. Whittaker, J. Am. Chem. Soc., 2011, 133, 11128-11131.

34 C. Boyer, A. H. Soeriyadi, P. B. Zetterlund and M. R. Whittaker, Macromolecules, 2011, 44, 8028-8033.

35 A. Anastasaki, C. Waldron, P. Wilson, C. Boyer, P. B. Zetterlund, M. R. Whittaker and D. M. Haddleton, ACS Macro Lett., 2013, 2, 896-900.

36 A. Anastasaki, V. Nikolaou, G. S. Pappas, G. Zhang, C. Wan, P. Wilson, T. P. Davis, M. R. Whittaker and D. M. Haddleton, Chem. Sci., 2014, 5, 3536-3542.

37 A. Anastasaki, V. Nikolaou, N. W. McCaul, A. Simula, J. Godfrey, C. Waldron, P. Wilson, K. Kempe and D. M. Haddleton, Macromolecules, 2015, 48, 1404-1411.

38 G. Gody, T. Maschmeyer, P. B. Zetterlund and S. Perrier, Nat. Commun., 2013, 4, 2505.

39 M. Minoda, M. Sawamoto and T. Higashimura, Macromolecules, 1990, 23, 4889-4895.

40 K. Satoh, S. Ozawa, M. Mizutani, K. Nagai and M. Kamigaito, Nat. Commun., 2010, 1, 6.

41 X. M. Tong, B. H. Guo and Y. B. Huang, Chem. Commun., 2011, 47, 1455-1457.

42 C.-H. Wang, Z.-Y. Song, X.-X. Deng, L.-J. Zhang, F.-S. Du and Z.-C. Li, Macromol. Rapid Commun., 2014, 35, 474-478.
43 B. Quiclet-Sire, G. Revol and S. Z. Zard, Tetrahedron, 2010, 66, 6656-6666.

44 S. Houshyar, D. J. Keddie, G. Moad, R. J. Mulder, S. Saubern and J. Tshanaktsidis, Polym. Chem., 2012, 3, 1879-1889.

45 E. G. Williams, B. Fairbanks, G. Moad, R. J. Mulder, E. Rizzardo and S. H. Thang, Polym. Chem., 2015, 6, 228232.

46 Y. Hibi, M. Ouchi and M. Sawamoto, Nat. Commun., 2016, 7, 11064 .

$47 \mathrm{~J} . \mathrm{Li}$ and J. He, ACS Macro Lett., 2015, 4, 372-376.

48 M. D. Watson and K. B. Wagener, Macromolecules, 2000, 33, 5411-5417.

49 M. D. Watson and K. B. Wagener, Macromolecules, 2000, 33, 8963-8970.

50 T. V. Baughman, J. C. Sworen and K. B. Wagener, Macromolecules, 2006, 39, 5208-5036.

51 T. V. Baughman, E. van der Aa and K. B. Wagener, Macromolecules, 2006, 39, 7015-7021.

52 T. V. Baughman, C. D. Chan, K. I. Winey and K. B. Wagener, Macromolecules, 2007, 40, 6564-6571.

53 G. Rojas and K. B. Wagener, Macromolecules, 2009, 42, 1934-1947.

54 S. Kobayashi, L. M. Pitet and M. A. Hillmyer, J. Am. Chem. Soc., 2011, 133, 5794-5797.

55 J. Zhang, M. E. Matta and M. A. Hillmyer, ACS Macro Lett., 2012, 1, 3507-3532.

56 J. Zhang, M. E. Matta, H. Martinez and M. A. Hillmyer, Macromolecules, 2013, 46, 2535-2543.

57 H. Martinez, N. Ren, M. E. Matta and M. A. Hillmyer, Polym. Chem., 2014, 5, 2535-2543.

58 W. J. Neary and J. G. Kennemur, Macromol. Rapid Commun., 2016, 37, 975-979.

59 J. Chiefari, R. T. A. Mayadunnem, G. Moad, E. Rizzardo and S. H. Thang, PCT Int. Appl. WO 99/31144, 1999.

60 G. Moad, J. Chiefari, Y. K. Chong, J. Krstina, R. T. A. Mayadunne, A. Postma, E. Rizzardo and S. H. Thang, Polym. Int., 2000, 49, 993-1001.

61 S. H. Thang, Y. K. Chong, R. T. A. Mayadunne, G. Moad and E. Rizzardo, Tetrahedron Lett., 1999, 40, 2435-2438. 